$(\mathrm{p}=0.037)$. There was no correlation between age and PMPs. There was no statistical significance between those with SLE with plaque and healthy controls or in EMP levels between the three groups. There was no correlation between EMPs or PMPs with disease activity as measured by BILAG.

SLE PMP v's Healthy Controls

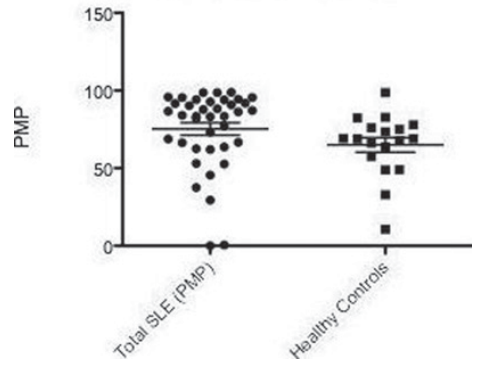

Conclusions: PMPs were raised in patients with SLE compared to the healthy controls regardless of whether there was atherosclerotic plaque evident on imaging. Therefore, raised PMPs were associated with SLE itself and did not stratify a subset of patients with subclinical CVD. Further research is required to define whether PMP are important in the pathogenesis of SLE and to clarify the relationship of subclinical CVD in larger cohorts.

Disclosure of Interest: None declared

DOI: 10.1136/annrheumdis-2017-eular.5525

\section{AB0132 ANTIPHOSPHOLIPID SYNDROME PATIENTS SHOW AN ALTERED PROFILE OF ENDOTHELIAL PROGENITOR CELLS AND ENDOTHELIAL MICROPARTICLES}

C. Barbati, F.R. Spinelli, F. Miranda, F. Ceccarelli, M. Vomero, L. Massaro, T. Colasanti, G. Valesini, C. Alessandri, F. Conti. Department of Internal Medicine and Medical Specialties, Lupus Clinic, Sapienza University of Rome, Rome, Italy

Background: Antiphospholipid Syndrome (APS) is an autoimmune disease characterized by recurrent thromboembolic events and pregnancy morbidity associated to the presence of specific serum antibodies directed against membrane phospholipids and proteic co-factors (1). Endothelial dysfunction represents the earlier and reversible stage of subclinical atherosclerosis that characterizes these patients. An altered profile of endothelial progenitor cells (EPCs) and endothelial microparticles (EMPs) could promote endothelial damage (2). Few studies suggested that EMP release is stimulated by circulating antiphospholipids (aPL). A previous study on EPC reservoir in 7 APS patients showed no difference compared to healthy subjects.

Objectives: Our aim was to evaluate circulating EPCs and EMPs in primary APS patients (PAPS).

Methods: We studied primary APS patients with previous thromboembolic events and sex and age-matched healthy controls (HC). Circulating EPCs was identified by flow cytometry analysis as CD34+/KDR+ positive cells isolated from peripheral blood mononuclear cells (PBMCs); EMPs was obtained by centrifugation of whole blood and quantified by flow cytometry (CD31+/CD41a-). Data were expressed a s mean \pm standard deviation or median (interquartile range) when appropriate; correlations between EPC and EMP levels with aPL were investigated by Spearman test. $P$ values $<0.05$ were considered statistically significant.

Results: We enrolled 12 PAPS patients (mean age $44 \pm 12$ years) and $12 \mathrm{HC}$. Compared to HC, PAPS patients showed a lower EPC percentage $0.01 \pm 0.006 \%$ vs $0.04 \pm 0.003 \%, \mathrm{p}=0.0008)$ and a higher EMP number $(104 \pm 80 \mathrm{MPs} /$ microliter vs $20 \pm 8, p<0.0001)$. EMPs number positively correlated with anticardiolipin and antibeta2 glicoprotein I, both IgM and $\operatorname{lgG}$ ( $p<0.05$ and $r>0.7$ for all correlations). Conclusions: The results of this study suggest that endothelial cells, activated by circulating $\mathrm{aPL}$, release EMPs that can perpetuate the endothelial damage. Moreover, our cohort of APS patients has a reduced number of circulating EPC that could contribute to the impairment of endothelial repair. Both the chronic endothelial damage and the lack of an efficient repair could contribute to the progression of atherosclerosis in PAPS patients.

References:

[1] Miyakis S, Lockshin MD, Atsumi T, Branch DW, Brey RL, Cervera R, Derksen RH, DE Groot PG, Koike T, Meroni PL, Reber G, Shoenfeld Y, Tincani A, Vlachoyiannopoulos PG, Krilis SA. International consensus statement on an update of the classification criteria for definiteantiphospholipid syndrome (APS). J. Thromb. Haemost. 2006 Feb;4:295-306.

[2] Bartoloni E, Alunno A, Bistoni O, Caterbi S, Luccioli F, Santoboni G, Mirabelli G, Cannarile F, Gerli R. Characterization of circulating endothelial microparticles and endothelial progenitor cells in primary Sjögren's syndrome: new markers of chronic endothelial damage? Rheumatology (Oxford). 2015 Mar;54:536-44.

Disclosure of Interest: None declared

DOI: 10.1136/annrheumdis-2017-eular.3712

\section{AB0133 BLOOD CONCENTRATION OF IMMUNOGLOBULIN BINDING PROTEIN 1 AS A BIOMARKER TO PREDICT LUPUS NEPHRITIS}

D.-H. Lim ${ }^{1}$, E.-J. Lee ${ }^{2}$, W.-J. Seo ${ }^{3}$, O.C. Kwon ${ }^{2}$, S. $\mathrm{Hong}^{2}$, C.-K. Lee ${ }^{2}$, B. Yoo ${ }^{2}$,

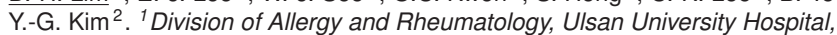
Ulsan; ${ }^{2}$ Division of Rheumatology, University of Ulsan College of Medicine, Asan Medical Center; ${ }^{3}$ Division of Rheumatology, Seoul Veterans Hospital, Seoul, Korea, Republic Of

Background: Systemic lupus erythematosus (SLE) is a chronic systemic autoimmune disease of unknown etiology, and renal involvement is an important factor associated with a high morbidity and mortality. Immunoglobulin binding protein 1 (IGBP1) is a phosphoprotein associated with $\mathrm{Ig}-\alpha$ of the B cell receptor complex. Intracellular IGBP1 interacts with the catalytic subunit of protein phosphatase (PP2A) and regulates differentiation, proliferation, and apoptosis of $B$ cells. Functional studies reported that high PP2A levels alter the phenotype and function of T cells in SLE patients. Recently, we reported that urinary IGBP1 levels were associated with the pathologic activity in lupus nephritis (LN). However, the role of plasma IGBP1 (pIGBP1) in the clinical features including the development of nephritis has not been identified in SLE.

Objectives: To determine the role of pIGBP1 as a biomarker related with LN.

Methods: Blood samples of SLE patients were collected between Jan 2009 and Dec 2010 in a tertiary hospital. The levels of plGBP1 were measured in SLE patients with $(n=44)$ or without $(n=39)$ nephritis, and healthy subjects $(\mathrm{n}=14)$. Clinical parameters including baseline characteristics, laboratory data, medications and SLE Disease Activity Index (SLEDAI) were collected from electronic medical record. Activity and chronicity index in renal pathology of LN were scored blindly by a renal pathologist. To identify factors related to the development of LN, Cox proportional hazard regression model and Kaplan-Meier curves were used.

Results: The concentrations of pIGBP1 in SLE patient were higher than those in healthy individual $(9.6 \pm 8.4 \mathrm{ng} / \mathrm{mL}$ vs $4.5 \pm 2.4 \mathrm{ng} / \mathrm{ml})$ and positively correlated with SLEDAI score. However, the concentrations were not different between LN and non-nephritis SLE and were not associated with activity index score in renal pathology. During follow-up more than 5 years, nephritis was developed in 8 patients $(20.5 \%)$ among 39 SLE patients who did not have renal involvement at baseline. Interestingly, levels of plGBP1 $(p=0.002), C R P(p=0.009)$, or anti-dsDNA antibody $(p=0.03)$ were significantly elevated in 8 patients who developed LN compared to who did not. Kaplan-Meier survival curve showed that initial pIGBP1 $(>10.71 \mathrm{ng} / \mathrm{mL})$ as well as anti-dsDNA $(>30.7 \mathrm{IU} / \mathrm{mL})$ were associated with high probability of LN development in the future.

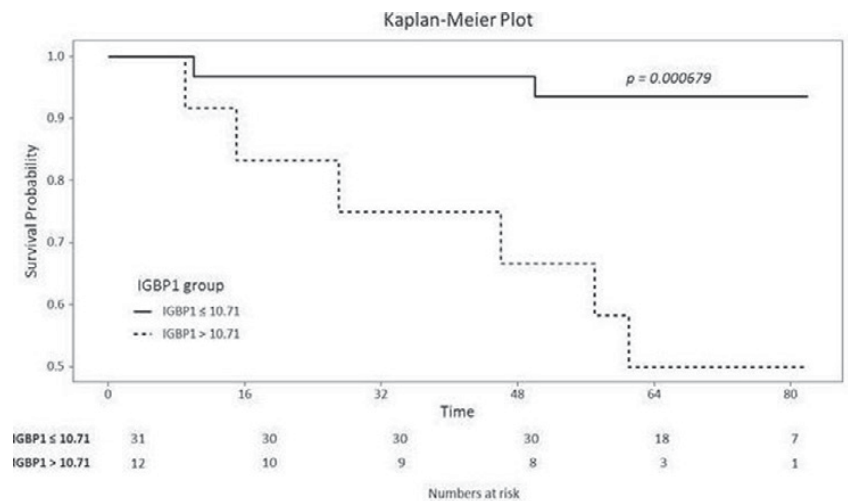

Conclusions: Based on our results, high concentration of plGBP1 could be a valuable marker to represent high SLE activity and a predictor for developing nephritis in SLE patients.

References:

[1] Lee EJ, Hong S, Lim DH, et al. Increased levels of immunoglobulin binding protein 1 are associated with disease activity including renal damage in patients with systemic lupus erythematosus. Presented in 2015 ACR/ARHP Annual meeting.

[2] Sunahori K, Nagpal K, Hedrich CM, et al. The catalytic subunit of protein phosphatase 2A (PP2Ac) promotes DNA hypomethylation by suppressing the phosphorylated mitogen-activated protein kinase/extracellular signal-regulated kinase (ERK) kinase (MEK)/phosphorylated ERK/DNMT1 protein pathway in T-cells from controls and systemic lupus erythematosus patients. J Biol Chem. 2013, 288(30):21936-44.

Acknowledgements: This work was supported by the National Research Foundation of Korea (NRF-2016R1A6A3A11930269).

Disclosure of Interest: None declared

DOI: 10.1136/annrheumdis-2017-eular.4292 